Article

\title{
Antimicrobial Resistance Profiles of Salmonella Isolates on Chickens Processed and Retailed at Outlets of the Informal Market in Gauteng Province, South Africa
}

\author{
Thelma M. Mokgophi ${ }^{1}$, Nomakorinte Gcebe ${ }^{2}$, Folorunso Fasina ${ }^{3}$ and Abiodun A. Adesiyun ${ }^{1,4, *}$ \\ 1 Department of Production Animal Studies, University of Pretoria, Private Bag X 04, Onderstepoort, \\ Pretoria 0110, South Africa; mt.mokgophi@yahoo.com \\ 2 Agricultural Research Council-Bacteriology and Zoonotic Diseases Diagnostic Laboratory, Onderstepoort \\ Veterinary Research, Private Bag X 05, Onderstepoort, Pretoria 0110, South Africa; GcebeN@arc.agric.za \\ 3 ECTAD, Food and Agriculture Organization of the UN, Dar es Salaam 14111, Tanzania \& Department of \\ Vet-erinary Tropical Diseases, University of Pretoria, Onderstepoort, Pretoria 0110, South Africa; \\ folorunso.fasina@fao.org \\ 4 Department of Paraclinical Sciences, School of Veterinary Medicine, University of the West Indies, \\ St. Augustine, Trinidad and Tobago \\ * Correspondence: Abiodun.adesiyun@up.ac.za
}

\section{check for} updates

Citation: Mokgophi, T.M.; Gcebe, N.; Fasina, F.; Adesiyun, A.A. Antimicrobial Resistance Profiles of Salmonella Isolates on Chickens Processed and Retailed at Outlets of the Informal Market in Gauteng Province, South Africa. Pathogens 2021, 10, 273. https://doi.org/ 10.3390 / pathogens 10030273

Academic Editor:

Masashi OKAMURA

Received: 3 February 2021

Accepted: 22 February 2021

Published: 1 March 2021

Publisher's Note: MDPI stays neutral with regard to jurisdictional claims in published maps and institutional affiliations.

Copyright: (c) 2021 by the authors. Licensee MDPI, Basel, Switzerland. This article is an open access article distributed under the terms and conditions of the Creative Commons Attribution (CC BY) license (https:// creativecommons.org/licenses/by/ $4.0 /)$.
Abstract: The study determined the antimicrobial resistance profiles of Salmonella on chickens processed and retailed at outlets of the informal markets in Gauteng province, South Africa. The study also investigated the relationship of antimicrobial resistant Salmonella to the source and type of samples and their serotypes. Carcass swabs, cloacal swabs and carcass drips were randomly collected from each of 151 slaughtered chickens from six townships. Isolation and identification were performed using standard and polymerase chain reaction (PCR) methods. The disc diffusion method was used to determine the resistance of Salmonella isolates to 16 antimicrobial agents and PCR to determine their serovars. Ninety-eight $(64.9 \%)$ of the 151 chickens were contaminated with Salmonella of which $94.9 \%$ (93/98) were resistant serovars. The frequency of antimicrobial resistance of Salmonella isolates was high to erythromycin $(94.9 \%)$ and spectinomycin $(82.7 \%)$ but was low to ciprofloxacin $(1.0 \%)$ and norfloxacin $(1.0 \%)(p<0.05)$. All 170 isolates of Salmonella tested exhibited resistance to one or more antimicrobial agents and the frequency varied significantly $(p<0.05)$ across the townships, the type of samples and the serovars. The prevalence of multidrug resistance (MDR) in Salmonella was $81.8 \%(139 / 170)$. Our findings pose zoonotic, food safety and therapeutic risks to workers and consumers of undercooked, contaminated chickens from these outlets.

Keywords: Salmonella in chickens; antimicrobial resistance profiles; Gauteng province; chicken; South Africa

\section{Introduction}

Globally, Salmonella spp. are known to cause high morbidity, mortality and economic losses in the poultry industry [1-4]. Additionally, Salmonella spp. are zoonotic agents with the potential to cause infection and disease in humans who consume improperly cooked contaminated poultry products [5-8]. In an effort to prevent, control or eradicate potential infection by Salmonella spp. and other pathogens in the poultry industry, antimicrobial agents are used for prophylaxis, therapy and as growth promoters [9-13]. In most developed countries, the use of antimicrobial agents is strictly controlled or banned for specific reasons in poultry through the enforcement of existing laws and regulations $[5,6,14]$. However, in most developing counties including South Africa, although laws exist to control the use of antimicrobial agents, there are challenges in their enforcement thereby resulting in their inappropriate use (overuse or abuse) [15,16]. In addition to the unregulated use of antimicrobial agents in South Africa, the Fertilizers, Farm Feed, Agricultural and Stock 
Remedies Act (Act 36, 1947) exists which legalizes the use of some antimicrobial agents, including tetracyclines, sulfonamides and trimethoprim. The Act also permits the purchase of over-the-counter antimicrobial agents without a prescription for use in the livestock industry $[13,17,18]$. This practice is likely to contribute to the development of resistant pathogens $[13,19]$ or the occurrence of antimicrobial residues in animal tissues with public health implications $[20,21]$.

In South Africa, over the years, outlets of the informal chicken market have emerged as popular venues for the population in the townships to access retailed chicken which is perceived to taste better than those from the commercial retail outlets. Furthermore, their prices are competitive and affordable, and they are conveniently located [22-24]. However, since these outlets are unregulated by health personnel and are considered illegal, concerns have been raised regarding their roadside locations, lack or inadequacy of potable water, and inadequate wastewater and solid waste disposal $[22,25,26]$. Sanitary practices have been reported to be poor, posing health risk to consumers of products from these outlets $[22,23,27]$. The chickens slaughtered at the informal market outlets usually originate from commercial poultry farms $[23,28]$ and small poultry enterprises. Therefore, the findings on the chickens processed at the outlets may reflect the occurrence of antimicrobial resistance at the farms from where they originated. There is also the possibility of carcass contamination being affected by practices at the outlets which may cause cross-contamination of processed chickens.

The rising threat of antimicrobial resistance (AMR) has prompted the development of national action plans whose five strategic objectives include, among others, optimization of surveillance and early detection of AMR for reporting local, regional, and national resistance patterns to optimize empirical and targeted antibiotic choices $[29,30]$.

There are a few reports of bacterial pathogens on chickens from the outlets of the informal market in Gauteng province, such as the prevalence and molecular characterization of Staphylococcus aureus isolates [22,31] and the isolation of Salmonella [32]. However, to date, there is no published documentation of the antimicrobial resistance profiles of Salmonella in chickens processed at outlets of the informal market in South Africa.

The current study determined the antimicrobial resistance profiles of Salmonella isolates recovered from chickens slaughtered, processed, and retailed at outlets of the informal market in Gauteng province. In addition, the study investigated the potential effect of township sources of chickens, types of samples processed and the serovars of isolates of Salmonella and their antimicrobial profiles. Another objective of the current study was to assess the potential effect of the practices at the outlets of the informal market on crosscontamination of carcass, cloacal swabs, and carcass drips by Salmonella. It is anticipated that the results from this study will contribute towards addressing AMR challenges in the country.

\section{Results}

\subsection{Selection of Informal Market Outlets Used in the Current Study}

A total of 151 chickens from which carcass swabs, cloacal swabs and carcass drips were each collected, originated from six townships (Atteridgeville, Garanguwa, Tembisa/Modise, Alexandra, Germiston and Soweto) across Gauteng province (Table 1).

\subsection{Isolation, Identification and Confirmation of Salmonella}

A total of 170 isolates of Salmonella that were recovered from chicken carcass swabs, cloacal swabs and carcass drips were identified and confirmed using conventional and PCR methods. 
Table 1. Prevalence of resistant Salmonella in chickens sampled from the informal market in Gauteng province, South Africa.

\begin{tabular}{|c|c|c|c|c|c|c|c|c|}
\hline \multicolumn{9}{|c|}{ No. (\%) of Resistant Salmonella Isolates from Chickens a Sampled from Townships: } \\
\hline & Atteridgeville & Garanguwa & Tembisa/Modise & Alexandra & Germiston & Soweto & & Total \\
\hline Antimicrobial Agent & $(n=4)^{b}$ & $(n=5)$ & $(n=1)$ & $(n=13)$ & $(n=20)$ & $(n=55)$ & $p$-Value & $(n=98)$ \\
\hline Erythromycin (E) & $4(100.0)$ & $3(60.0)$ & $1(100.0)$ & $10(76.9)$ & $20(100.0)$ & $55(100.0)$ & $<0.001$ & $93(94.9)$ \\
\hline Oxytetracycline (OXT) & $2(50.0)$ & $0(0.0)$ & $0(0.0)$ & $5(38.5)$ & $11(55.0)$ & $46(83.6)$ & $<0.001$ & $64(65.3)$ \\
\hline Chloramphenicol (C) & $0(0.0)$ & $0(0.0)$ & $0(0.0)$ & $0(0.0)$ & $0(0.0)$ & $2(3.6)$ & 0.902 & $2(2.0)$ \\
\hline Kanamycin $(\mathrm{K})$ & $1(25.0)$ & $0(0.0)$ & $0(0.0)$ & $0(0.0)$ & $0(0.0)$ & $1(1.8)$ & 0.044 & $2(2.0)$ \\
\hline Nalidixic acid (NA) & $0(0.0)$ & $0(0.0)$ & $0(0.0)$ & $0(0.0)$ & $0(0.0)$ & $1(1.8)$ & 0.978 & $1(1.0)$ \\
\hline Streptomycin (S) & $3(75.0)$ & $0(0.0)$ & $0(0.0)$ & $6(46.2)$ & $15(75.0)$ & $49(89.1)$ & $<0.001$ & $73(74.5)$ \\
\hline Spectinomycin (SPE) & $4(100.0)$ & $0(0.0)$ & $0(0.0)$ & $7(53.8)$ & $19(95.0)$ & $51(87.9)$ & $<0.001$ & $81(82.7)$ \\
\hline Ciprofloxacin (CIP) & $0(0.0)$ & $0(0.0)$ & $0(0.0)$ & $0(0.0)$ & $1(5.0)$ & $0(0.0)$ & 0.558 & $1(1.0)$ \\
\hline Ampicillin (AMP) & $0(0.0)$ & $0(0.0)$ & $0(0.0)$ & $0(0.0)$ & $2(10.0)$ & $3(5.5)$ & 0.815 & $5(5.1)$ \\
\hline Cefotaxime (CET) & $1(25.0)$ & $0(0.0)$ & $0(0.0)$ & $1(7.7)$ & $6(30.0)$ & $7(12.7)$ & 0.351 & $15(15.3)$ \\
\hline Doxycycline (DO) & $2(50.0)$ & $0(0.0)$ & $0(0.0)$ & $4(30.8)$ & $10(50.0)$ & $42(76.4)$ & 0.001 & $58(59.2)$ \\
\hline Gentamycin (CN) & $0(0.0)$ & $0(0.0)$ & $0(0.0)$ & $0(0.0)$ & $2(10.0)$ & $0(0.0)$ & 0.158 & $2(2.0)$ \\
\hline $\begin{array}{l}\text { Amoxicillin-clavulanic } \\
\text { acid (AMOX) }\end{array}$ & $0(0.0)$ & $0(0.0)$ & $0(0.0)$ & $1(7.7)$ & $1(5.0)$ & $2(3.6)$ & 0.968 & $4(4.1)$ \\
\hline $\begin{array}{c}\text { Sulfamethoxazole- } \\
\text { trimethoprim } \\
\text { (SXT) }\end{array}$ & $2(50.0)$ & $0(0.0)$ & $0(0.0)$ & $4(30.8)$ & $1(5.0)$ & $2(3.6)$ & 0.003 & $9(9.2)$ \\
\hline Ceftazidime (CAZ) & $0(0.0)$ & $0(0.0)$ & $0(0.0)$ & $0(0.0)$ & $2(10.0)$ & $1(1.8)$ & 0.513 & $3(3.1)$ \\
\hline Norfloxacin (NOR) & $0(0.0)$ & $0(0.0)$ & $0(0.0)$ & $1(7.7)$ & $0(0.0)$ & $0(0.0)$ & 0.252 & $1(1.0)$ \\
\hline$p$-value & $<0.001$ & $<0.001$ & 0.382 & $<0.001$ & $<0.001$ & $<0.001$ & & \\
\hline
\end{tabular}

${ }^{a}$ Isolates of Salmonella originally recovered from 151 chickens distributed across six townships comprising Atteridgeville (23), Garanguwa (18), Tembisa/Modise (10), Alexandra (20), Germiston (20), and Soweto (60), respectively as reported earlier by Mokgophi et al. [32]. b For a total of 98 Salmonella-positive chickens, the chicken-specific frequency of antimicrobial resistant Salmonella recovered was determined.

\subsection{Determination of Salmonella Serovars by PCR and Conventional Serotyping}

For the 170 isolates of Salmonella where the serovars were determined using both PCR and conventional slide agglutination test, a total of nine serovars were detected, namely, Bovismorbificans, Hadar, Dublin, Enteritidis, Mbandaka, Saintpaul, Thompson, Infantis, and Agona at varying frequencies.

\subsection{Selection of Antimicrobial Agents Used in the Study}

Overall, the resistance of the 170 isolates of Salmonella to 16 antimicrobial agents that belonged to eight antimicrobial classes (Aminoglycosides, Beta lactams, Cephalosporins, Fluoroquinolones, Macrolides, Phenicols, Sulphonamides, and Tetracyclines) were determined and presented in Table 1.

\subsection{Frequency of Chickens Contaminated with Salmonella}

Of a total of 151 chickens (packed in individual bags) tested for the carriage of Salmonella in their carcass swabs, cloacal swabs and/or carcass drips, 98 (64.9\%) were positive for the pathogen.

2.6. Detection of Resistance to Antimicrobial Agents According to the Townships, Types of Samples, and the Serovars of Salmonella

2.6.1. Frequency of Detection of Resistant Salmonella in Chickens

The prevalence of antimicrobial resistant Salmonella in the 98 chickens positive for Salmonella was $94.6 \%$ (93/98) with the recovered isolates having exhibited resistance to one or more antimicrobial agents as shown in Table 1. For the six townships, antimicrobial resistance was highest to erythromycin, ranging from $60.0 \%$ (Ranguwa) to 100.0\% (Atteridgeville, Tembisa/Modise and Soweto). Overall, for the 16 antimicrobial agents tested, the prevalence of resistance among Salmonella was high to erythromycin, 94.9\% (93/98), spectinomycin, $82.7 \%(81 / 98)$ and streptomycin, $74.5 \%(73 / 98)$ but low to nalidixic acid, $1.0 \%(1 / 98)$, ciprofloxacin, $1.0 \%(1 / 98)$ and norfloxacin, $1.0 \%(1 / 98)$. The occurrence of resistant to one or more of the 16 antimicrobial agents within the townships was $13(81.3 \%)$, $12(75.0 \%), 9(56.3 \%), 8(50.0 \%), 1(6.3 \%)$, and 1 (6.3\%) for Salmonella isolates recovered from chickens sampled in outlets from Soweto, Germiston, Alexandra, Atteridgeville, Ranguwa, and Tembise/Modisa, respectively, and the differences were statistically signifi- 
cant $(p=0.0002)$. Overall, the frequency of resistance to antimicrobial agents in Salmonella isolates varied significantly $(p<0.001)$ between and within townships (Table 1$)$.

\subsubsection{Frequency of Detection of Resistant Salmonella by Type of Sample Processed}

Table 2 shows the frequency of resistance to antimicrobial agents among the isolates of Salmonella recovered from three types of samples (carcass, cloacal swabs and carcass drips). A total of 170 isolates of Salmonella comprising 54, 56 and 60 recovered from carcass swabs, cloacal swabs and carcass drips, respectively, were analyzed. All (100.0\%) the Salmonella isolates exhibited resistance to one or more antimicrobial agent. Again, the frequency of resistance of Salmonella isolates from the three types of samples was high to erythromycin, $100.0 \%$ (170/170), spectinomycin, 88.8\% (151/170) and streptomycin, $80.0 \%(136 / 170)$ but considerably low to ciprofloxacin, $0.6 \%(1 / 170)$, chloramphenicol, $1.8 \%(2 / 170)$ and norfloxacin, $1.8 \%(2 / 170)$. The differences were statistically significant $(p<0.05)$.

Table 2. Prevalence of antimicrobial resistance in Salmonella isolates by type of sample.

\begin{tabular}{|c|c|c|c|c|}
\hline \multirow[b]{3}{*}{ Antimicrobial Agent } & \multicolumn{4}{|c|}{ No. (\%) of Resistant Salmonella Isolates by Type of Sample Collected: } \\
\hline & Carcass Swab & Cloacal Swab & Carcass Drip & \multirow{2}{*}{$p$-Value } \\
\hline & $(n=54)^{a}$ & $(n=56)^{a}$ & $(n=60)^{a}$ & \\
\hline Erythromycin (E) & $54(100.0)$ & $56(100.0)$ & $60(100.0)$ & NA \\
\hline Oxytetracycline (OXT) & $37(68.5)$ & $44(78.6)$ & $46(76.7)$ & 0.436 \\
\hline Chloramphenicol (C) & $0(0.0)$ & $0(0.0)$ & $2(3.3)$ & 0.156 \\
\hline Kanamycin $(\mathrm{K})$ & $0(0.0)$ & $4(7.1)$ & $1(1.7)$ & 0.066 \\
\hline Nalidixic acid (NA) & $0(0.0)$ & $1(1.8)$ & $1(1.7)$ & 0.623 \\
\hline Streptomycin (S) & $34(63.0)$ & $48(85.7)$ & $54(90.0)$ & $<0.001$ \\
\hline Spectinomycin (SPE) & $46(85.2)$ & $51(91.1)$ & $54(90.0)$ & 0.580 \\
\hline Ciprofloxacin (CIP) & $0(0.0)$ & $1(1.8)$ & $0(0.0)$ & 0.359 \\
\hline Ampicillin (AMP) & $0(0.0)$ & $5(8.9)$ & $3(5.0)$ & 0.086 \\
\hline Cefotaxime (CET) & $2(3.7)$ & $13(23.2)$ & $9(15.0)$ & 0.0130 \\
\hline Doxycycline (DO) & $35(64.8)$ & $12(21.4)$ & $42(70.0)$ & $<0.001$ \\
\hline Gentamycin (CN) & $0(0.0)$ & $3(5.4)$ & $3(5.0)$ & 0.234 \\
\hline $\begin{array}{l}\text { Amoxicillin-clavulanic acid } \\
\text { (AMOX) }\end{array}$ & $2(3.7)$ & $4(7.1)$ & $1(1.7)$ & 0.327 \\
\hline $\begin{array}{c}\text { Sulfamethoxazole-trimethoprim } \\
(\mathrm{SXT})\end{array}$ & $0(0.0)$ & $5(8.9)$ & $6(10.0)$ & 0.063 \\
\hline Ceftazidime (CAZ) & $1(1.9)$ & $4(7.1)$ & $1(1.7)$ & 0.201 \\
\hline Norfloxacin (NOR) & $0(0.0)$ & $1(1.8)$ & $1(1.7)$ & 0.623 \\
\hline$p$-value & $<0.001$ & $<0.001$ & $<0.001$ & \\
\hline
\end{tabular}

${ }^{a}$ A total of 170 isolates of Salmonella recovered from carcass swabs $(n=54)$, cloacal swabs $(n=56)$, and carcass drips $(n=60)$, based on their serovars were tested for their resistance to antimicrobial agents to determine sample type-specific frequency of resistance; NA: Not applicable.

Across and within the three types of samples processed, the frequency of resistance to antimicrobial agents differed significantly $(p<0.001)$.

\subsubsection{Frequency of Detection of Resistant Strains among Serotypes of Salmonella}

The frequency of antimicrobial resistant Salmonella among the serovars detected is displayed in Table 3. Of a total of 170 isolates tested, $103(60.6 \%)$ were typable. The frequency of detection of the serovars among the 103 typable isolates of S. enterica was as follows: Bovismorbificans, 39.8\%; Hadar, 17.5\%; Dublin, 12.6\%; Enteritidis, 10.7\%; Mbandaka, 8.7\%; Saintpaul, 5.8\%; Thompson, 1.9\%, Infantis, 1.9\%, and Agona, 1.0\%. The differences were statistically significant $(p<0.05)$. 
Table 3. Frequency of resistant Salmonella isolates belonging to different serovars isolated from chickens in the informal market in Gauteng province, South Africa.

\begin{tabular}{|c|c|c|c|c|c|c|c|c|c|c|c|}
\hline \multirow[b]{3}{*}{ Antimicrobial Agents } & \multicolumn{10}{|c|}{ No. (\%) of Salmonella Isolates Belonging to Nine Serotypes Resistant to Antimicrobial Agents: } & \multirow[b]{2}{*}{ Total } \\
\hline & Bovismorbificans & Hadar & Dublin & Enteritidis & Mbandaka & Saintpaul & Thompson & Infantis & Agona & & \\
\hline & $(n=41)^{\mathrm{a}}$ & $(n=18)$ & $(n=13)$ & $(n=11)$ & $(n=9)$ & $(n=6)$ & $(n=2)$ & $(n=2)$ & $(n=1)$ & $p$-Value & $(n=103)$ \\
\hline Erythromycin & $41(100.0)$ & $18(100.0)$ & $13(100.0)$ & $11(100.0)$ & $9(100.0)$ & $6(100.0)$ & $2(100.0)$ & $2(100.0)$ & $1(100.0)$ & NA & 103 \\
\hline Oxytetracycline & $38(92.7)$ & $11(61.1)$ & $10(76.9)$ & $9(81.8)$ & $7(77.8)$ & $4(66.7)$ & $1(50.0)$ & $1(50.0)$ & $1(100.0)$ & 0.188 & $84(81.6)$ \\
\hline Chloramphenicol & $0(0.0)$ & $1(5.6)$ & $0(0.0)$ & $1(9.1)$ & $0(0.0)$ & $0(0.0)$ & $0(0.0)$ & $0(0.0)$ & $0(0.0)$ & 0.686 & $2(1.9)$ \\
\hline $\begin{array}{l}\text { Kanamycin } \\
\text {. }\end{array}$ & $1(2.4)$ & $1(5.6)$ & $0(0.0)$ & $0(0.0)$ & $0(0.0)$ & $0(0.0)$ & $0(0.0)$ & $0(0.0)$ & $0(0.0)$ & 0.976 & $2(1.9)$ \\
\hline Nalidixic acid & $0(0.0)$ & $1(5.6)$ & $0(0.0)$ & $0(0.0)$ & $0(0.0)$ & $0(0.0)$ & $0(0.0)$ & $0(0.0)$ & $0(0.0)$ & 0.782 & $1(1.0)$ \\
\hline Streptomycin & $38(92.7)$ & $15(83.3)$ & $11(84.6)$ & $9(81.8)$ & $8(88.9)$ & $2(33.3)$ & $1(50.0)$ & $1(50.0)$ & $1(100.0)$ & 0.029 & 83.5 \\
\hline Spectinomycin & 39 (95.1) & $16(88.9)$ & $12(92.3)$ & $9(81.8)$ & $7(77.8)$ & $6(100.0)$ & $1(50.0)$ & $1(50.0)$ & $1(100.0)$ & 0.213 & $92(89.3)$ \\
\hline Ciprofloxacin & $0(0.0)$ & $0(0.0)$ & $0(0.0)$ & $0(0.0)$ & $0(0.0)$ & $0(0.0)$ & $0(0.0)$ & $0(0.0)$ & $0(0.0)$ & NA & 0 \\
\hline Ampicillin & $0(0.0)$ & $0(0.0)$ & $0(0.0)$ & $1(9.1)$ & $0(0.0)$ & $0(0.0)$ & $0(0.0)$ & $0(0.0)$ & $0(0.0)$ & 0.391 & $1(1.0)$ \\
\hline Cefotaxime & $1(2.4)$ & $3(16.7)$ & $3(23.1)$ & $2(18.2)$ & $2(22.2)$ & $0(0.0)$ & $1(50.0)$ & $0(0.0)$ & $0(0.0)$ & 0.205 & $12(11.7)$ \\
\hline Doxycycline & $34(82.9)$ & $13(7$ & $9(69.2)$ & $9(81.8)$ & 5 (55.6) & $4(66.7)$ & $0(0.0)$ & $1(50.0)$ & $1(100.0)$ & 0.227 & 76 (73.8) \\
\hline Gentamycin & $2(4.9)$ & $0(0.0)$ & $0(0.0)$ & $0(0.0)$ & $0(0.0)$ & $0(0.0)$ & $0(0.0)$ & $0(0.0)$ & $0(0.0)$ & 0.929 & $2(1.9)$ \\
\hline $\begin{array}{l}\text { Amoxycillin } \\
\text { Clavulanic acid }\end{array}$ & $3(7.3)$ & $0(0.0)$ & $0(0.0)$ & $2(18.2)$ & $0(0.0)$ & $0(0.0)$ & $0(0.0)$ & $0(0.0)$ & $0(0.0)$ & 0.497 & $5(4.9)$ \\
\hline $\begin{array}{l}\text { Sulfamethoxazole- } \\
\text { trimethoprim }\end{array}$ & $2(4.9)$ & $1(5.6)$ & $0(0.0)$ & $1(9.1)$ & $1(11.1)$ & $0(0.0)$ & $0(0.0)$ & $0(0.0)$ & $0(0.0)$ & 0.965 & $5(4.9)$ \\
\hline Ceftazidime & $1(2.4)$ & $0(0.0)$ & $0(0.0)$ & $1(9.1)$ & $0(0.0)$ & $0(0.0)$ & $0(0.0)$ & $0(0.0)$ & $0(0.0)$ & 0.856 & $2(1.9)$ \\
\hline Norfloxacin & $\begin{array}{l}1(2.4) \\
<0.001\end{array}$ & $0(0.0)$ & $0(0.0)$ & $0(0.0)$ & $0(0.0)$ & $0(0.0)$ & $0(0.0)$ & $0(0.0)$ & $0(0.0)$ & 0.992 & $1(1.0)$ \\
\hline$p$-value & $<0.001$ & $<0.001$ & $<0.001$ & $<0.001$ & $<0.001$ & $<0.001$ & 0.220 & 0.220 & 0.382 & & \\
\hline
\end{tabular}

a Among all the 41 isolates that belonged to serovar Bovismorbificans, resistance was exhibited to 12 different antimicrobial agents tested (i.e., $75.0 \%, 12 / 16$ ) by at least one isolate.

For the nine serovars of Salmonella detected, the frequency of resistance to one or more of the 16 antimicrobial agents varied considerably but a statistically significant difference was detected only for streptomycin $(p<0.029)$. All the typable isolates of the nine serovars were susceptible to nalidixic acid and ciprofloxacin.

For the 16 antimicrobial agents tested, the spectrum of resistance exhibited by isolates of Salmonella varied significantly across serovars, i.e., at least one isolate of each serovar exhibiting resistance to the different antimicrobial agents tested, and was high for Bovismorbificans, $75 \%(12 / 16)$, Enteritidis, 68.8\% (11/16) and Hadar, 62.5\% (10/16) but low at $31.3 \%$ (5/16) each for serovars Saintpaul, Thompson, Infantis, and Agona. The differences were statistically significant $(p<0.05)$.

Within the nine serovars of Salmonella isolates tested, the prevalence of resistance to one or more of the 16 antimicrobial agents was detected for Bovismorficans $(p<0.01)$, Hadar $(p<0.01)$, Dublin $(p<0.01)$, Enteritidis $(p<0.01)$, Mbandaka $(p<0.01)$, and Saintpaul $(p<0.01)$.

\subsubsection{Prevalence of Resistance Patterns and Multi-resistant Isolates of Salmonella}

A total of 13, 21 and 22 resistance patterns were detected in the isolates of Salmonella from carcass swabs, cloacal swabs and carcass drips, respectively. The same predominant resistance pattern, erythromycin-oxytetracycline-streptomycin-spectinmycin-doxycycline (E-OXT-S-SPE-DO) was detected in the three types of samples at a frequency of $42.6 \%, 41.1 \%$ and $43.3 \%$ of which 35 were multidrug resistant (MDR) (Table 4). Overall, the frequency of MDR among the Salmonella isolates was 81.8\% (139/170) having exhibited resistance to three or more antimicrobial agents that belonged to eight antimicrobial classes tested. The occurrence of MDR in Salmonella isolates was 72.2\% (39/54), 92.9\% (52/56) and 80.0\% $(48 / 60)$ in carcass swabs, cloacal swabs and carcass drips, respectively. The differences were statistically significant $(p=0.0308)$. Of the 170 isolates of resistant Salmonella, $31(18.2 \%)$ were resistant to antimicrobial agents that belonged to less than three antimicrobial classes (i.e., non-MDR). These were E-SPE (7, 4.1\%), E (14, 8.2\%), E-S-SPE (7, 4.1\%), E-OXT-DO (2, $1.2 \%)$, and E-S (1, $0.6 \%)$. The frequency of MDR among the isolates of Salmonella was $81.8 \%$ $(139 / 170)$. The number of antimicrobial agents in the patterns obtained for MDR isolates varied from 3 to 10 as follows: 3 antimicrobial agents $(5,3.6 \%), 4(23,16.5), 5(76,54.7 \%)$, $6(23,16.5 \%), 7(8,5.8 \%), 8(2,1.4 \%), 9(1,0.7 \%)$, and $10(1,0.7 \%)$. Among MDR isolates, the predominant resistance pattern exhibited by Salmonella isolates from the three types of samples was E-OXT-S-SPE-DO, 51.8\% (72/139). 
Table 4. Resistance patterns exhibited by Salmonella isolates recovered by types of samples collected.

\begin{tabular}{|c|c|c|c|c|}
\hline \multirow[b]{3}{*}{ Resistance Pattern ${ }^{\text {a }}$} & \multicolumn{4}{|c|}{ No. (\%) of Isolates of Salmonella with Resistance Patterns from: } \\
\hline & No. of Antimicrobial & Carcass Swabs & Cloacal Swabs & Carcass Drips \\
\hline & Agents in Pattern & $(n=54)$ & $(n=56)$ & $(n=60)$ \\
\hline E-OXT-S-SPE-DO & 5 & $23(42.6)$ & $23(41.1)$ & $26(43.3)$ \\
\hline E-SPE & 2 & $6(11.1)$ & $0(0.0)$ & $1(1.7)$ \\
\hline E-OXT-SPE-DO & 4 & $6(11.1)$ & $0(0.0)$ & $0(0.0)$ \\
\hline $\mathrm{E}$ & 1 & $6(11.1)$ & $2(3.6)$ & $6(10.0)$ \\
\hline E-OXT-S-SPE-D0-AMOX & 6 & $2(3.7)$ & $0(0.0)$ & $0(0.0)$ \\
\hline E-S-SPE-DO & 4 & $2(3.7)$ & $1(1.8)$ & $0(0.0)$ \\
\hline E-OXT-S-SPE & 4 & $2(3.7)$ & $0(0.0)$ & $0(0.0)$ \\
\hline E-OXT-S-SPE-CET-DO & 6 & $0(0.0)$ & $5(8.9)$ & $3(5.0)$ \\
\hline E-OXT-S-DO & 4 & $0(0.0)$ & $3(5.4)$ & $1(1.7)$ \\
\hline E-SPE-CET & 3 & $0(0.0)$ & $2(3.6)$ & $0(0.0)$ \\
\hline E-S-SPE-CET & 4 & $1(1.9)$ & $2(3.6)$ & $0(0.0)$ \\
\hline E-S-SPE & 3 & $2(3.7)$ & $2(3.6)$ & $3(5.0)$ \\
\hline E-OXT-S-SPE-DO-CN & 6 & $0(0.0)$ & $2(3.6)$ & $0(0.0)$ \\
\hline E-OXT-K-S-SPE-DO & 6 & $0(0.0)$ & $2(3.6)$ & $0(0.0)$ \\
\hline E-OXT-S-SPE & 4 & $0(0.0)$ & $0(0.0)$ & $3(5.0)$ \\
\hline E-OXT-S-SPE-DO-SXT-NOR & 7 & $0(0.0)$ & $0(0.0)$ & $2(3.3)$ \\
\hline E-0XT-S-SPE-DO-SXT & 6 & $0(0.0)$ & $1(1.8)$ & $2(3.3)$ \\
\hline E-SPE-DO & 3 & $1(1.9)$ & $0(0.0)$ & $1(1.7)$ \\
\hline E-OXT-S & 3 & $1(1.9)$ & $0(0.0)$ & $0(0.0)$ \\
\hline E-OXT-DO & 3 & $1(1.9)$ & $0(0.0)$ & $1(1.7)$ \\
\hline E-OXT-S-SPE-CET-DO-CEFT & 7 & $1(1.9)$ & $0(0.0)$ & $0(0.0)$ \\
\hline E-OXT-S-SPE-CET-D0-SXT & 7 & $0(0.0)$ & $1(1.8)$ & $0(0.0)$ \\
\hline E-OXT-K-S-SPE-DO-SXT & 7 & $0(0.0)$ & $1(1.8)$ & $0(0.0)$ \\
\hline E-OXT-K-S-SPE-AMP-DO-SXT & 8 & $0(0.0)$ & $1(1.8)$ & $0(0.0)$ \\
\hline E-SPE-CET-AMOX-CEFT & 5 & $0(0.0)$ & $2(3.6)$ & $0(0.0)$ \\
\hline E-SPE-AMP-CET-CN-CEFT & 6 & $0(0.0)$ & $1(1.8)$ & $0(0.0)$ \\
\hline E-OXT-S-SPE-AMP-DO-AMOX-CEFT & 8 & $0(0.0)$ & $1(1.8)$ & $0(0.0)$ \\
\hline E-OXT-S-SPE-AMP-CET-DO-AMOX-CEFT & 9 & $0(0.0)$ & $1(1.8)$ & $0(0.0)$ \\
\hline E-OXT-S-SPE-DO-SXT & 6 & $0(0.0)$ & $1(1.8)$ & $0(0.0)$ \\
\hline E-OXT-S-SPE-AMP-DO-AMOX & 7 & $0(0.0)$ & $1(1.8)$ & $0(0.0)$ \\
\hline E-OXT-K-S-SPE-DO & 6 & $0(0.0)$ & $1(1.8)$ & $0(0.0)$ \\
\hline E-OXT-S-SPE-DO-AMOX-SXT & 7 & $0(0.0)$ & $0(0.0)$ & $1(1.7)$ \\
\hline E-S & 2 & $0(0.0)$ & $0(0.0)$ & $1(1.7)$ \\
\hline E-S-SPE-AMP-CET-CN-CEFT & 7 & $0(0.0)$ & $0(0.0)$ & $1(1.7)$ \\
\hline E-S-SPE-AMP-CET-CN & 6 & $0(0.0)$ & $0(0.0)$ & $1(1.7)$ \\
\hline E-S-SPE-CET-DO & 5 & $0(0.0)$ & $0(0.0)$ & $1(1.7)$ \\
\hline E-OXT-S-SPE-SXT & 5 & $0(0.0)$ & $0(0.0)$ & $1(1.7)$ \\
\hline E-OXT-C-S-SPE-DO & 6 & $0(0.0)$ & $0(0.0)$ & $1(1.7)$ \\
\hline E-OXT-S-SPE-DO-CN & 6 & $0(0.0)$ & $0(0.0)$ & $1(1.7)$ \\
\hline E-OXT-C-K-S-SPE-CET-DO-SXT & 10 & $0(0.0)$ & $0(0.0)$ & $1(1.7)$ \\
\hline
\end{tabular}

a E-erythromycin, OXT—-tetracycline, C-chloramphenicol, K-kanamycin, NA—nalidixic acid, S-streptomycin, SPE-spectinomycin, CIP-ciprofloxacin, AMP—ampicillin, CET—cefotaxime, DO—doxycycline, CN-gentamycin, AMOX-amoxicillin-clavulanic acid, SXT—sulfamethoxazole-trimethoprim, CAZ—ceftazidime, NOR—norfloxacin.

\section{Discussion}

Our study demonstrated, for the first time in South Africa, a very high prevalence, 94.9\% (93/98) of resistant Salmonella on chicken carcasses purchased from the informal market in South Africa. Of the 170 Salmonella isolates recovered from carcass swabs, cloacal swabs and carcass drips, all (100\%) exhibited resistance to antimicrobial agents. This study strategy was used because of the unique situation in 'wet markets', such as the informal market outlets in Gauteng province which have limited physical infrastructure, lack a potable water supply, have poor drainage, and inadequate wastewater and solid waste disposal [25]. Most importantly, as reported earlier [25], slaughtered chickens are rinsed in infrequently changed water in drums and buckets. The implication is that 
there is a high potential for cross-contamination among several carcasses with resistant Salmonella during the rinsing process. Considering that chickens in the informal market are bagged fresh in nylon bags for sale, the rationale of the study was therefore to collect three types of samples (carcass swabs, cloacal swabs and carcass drips) from each bag. This approach allowed a comparison of the serovars and resistance patterns of Salmonella from the three sources to provide evidence of cross contamination. Additionally, the cloacal swab samples were likely to be indicative of the prevalence and resistance patterns from the farms from where the live chickens originated. It cannot be over-emphasized that the high prevalence of resistant Salmonella in the chickens sampled, poses a risk of infection or clinical salmonellosis in consumers of improperly cooked Salmonella-contaminated chickens. There are also potential therapeutic and public health implications for workers and implications for workers at these outlets.

Overall, across the six townships, the prevalence of resistant Salmonella was particularly high to erythromycin $(99.6 \%)$, spectinomycin $(92.6 \%)$, streptomycin $(82.5 \%)$, oxytetracycline $(78.0 \%)$, and doxycycline $(76.1 \%)$, which are commonly used by poultry farmers (commercial and backyard) and veterinarians in the country. The detected high prevalence of resistant Salmonella in our study has implications for the poultry farms in Gauteng province because all the chickens (broilers, culled breeders and spent hens) processed at the informal market outlets originated from these farms. The overall high prevalence of resistant Salmonella may be indicative of improper use or misuse of antimicrobial agents for prophylaxis, growth promotion and therapy which may be as a result of noncompliance by farmers or failure by the authorities to enforce existing legislations [9-13]. The outcome of such a practice is an increase in the prevalence of resistance among pathogens, including Salmonella, and therefore resultant therapeutic failure. High prevalence of resistance to antimicrobial agents has been documented for Salmonella and other pathogens in the livestock industry in South Africa [17-19,33], and in other countries [34]. Additionally, infection of poultry with resistant Salmonella on farms has the potential to cause high morbidity and mortality in chickens as earlier reported [1-4,35]. Furthermore, the potential zoonotic spread of resistant Salmonella to workers has been reported [36-38].

The high prevalence of resistance to the antimicrobial agents such as erythromycin, spectinomycin, streptomycin, tetracycline, and doxycycline by Salmonella in our study agrees with published reports of poultry-associated Salmonella by others [39-41]. It is pertinent to mention that in South Africa, the tetracyclines are the most commonly used or over-used antibiotics in the livestock industry, particularly in poultry, to treat bacterial infections such as Salmonella spp. and Escherichia coli, among others [15,16]. This is due to the fact that they are comparatively inexpensive, readily available as over-the-counter veterinary drugs $[13,18]$, and their use is allowed by the South Africa Fertilizers, Farm Feed, Agricultural and Stock Remedies Act (Act 36, 1947). The high prevalence of resistance to tetracycline and doxycycline among Salmonella detected in our study is therefore not unexpected. The prevalence of resistance to six antimicrobial agents (tetracycline, doxycycline, streptomycin, spectinomycin, and sulfamethoxazole-trimethoprim) found in Salmonella on chickens sampled and processed at the outlets in our study varied significantly across the townships as a result of the origin of the live chickens. This may be due, in part, to the variable use or abuse of the antimicrobial agents on the farms from where the chickens were sourced. This aspect did not form part of our study. The lack of compliance with legislation governing the type and number of antimicrobial agents used in the livestock and human medicine in South African may be a causative factor in the development of antimicrobial resistance of the Salmonella isolates studied [17,18,42], as similarly reported by others elsewhere $[43,44]$. Another potential contributing factor to the significantly different prevalence of resistance to antimicrobial agents among Salmonella across townships is the practice of contractors purchasing live chickens from commercial broiler and layer farms across the province and supplying them to the outlets of the informal market [22,28]. Geographical location and farm size are some of the factors that have been reported to significantly facilitate the carriage and spread of Salmonella [45-48]. 
The variable prevalence of resistant Salmonella on these farms will therefore be reflected in our findings at the outlets. This explanation is further supported by the finding of similarly high prevalence $(100.0 \%)$ of resistant Salmonella in the cloacal swab samples which also varied significantly across the townships and measured the carriage of the pathogen in the flocks from where they originated. This is because cloacal swabs of chickens were not subjected to potential cross-contamination experienced by carcass swabs and carcass drips during processing at the outlets.

Similarly, high prevalence of resistant Salmonella has been reported for chickens slaughtered in the outlets of the 'wet market' in other countries, such as in the cecal contents of chickens slaughtered in 'pluck shops' in Trinidad [46] where 100.0\% of the Salmonella isolates were resistant to antimicrobial agents which included 10 of the 16 used in the current study and in India where $100.0 \%$ (51/51) of Salmonella isolates from the rectal swabs in poultry exhibited resistance to 16 antimicrobial agents [49].

Equally of potential therapeutic importance was the detection of a very high $(94.0 \%)$ prevalence of MDR isolates of Salmonella. Other studies of the pathogens of poultry in South Africa have similarly reported a high prevalence of MDR in Salmonella isolates in chickens and other livestock, thus highlighting their therapeutic and public health implications [42,50-56]. The prevalence of MDR in the current study is higher than was reported, also using the disc diffusion method, for Salmonella from chickens (caeca) in Trinidad, 14.3\% [46], Portugal, 75.0\% [57], China, 80.0\% [58], and in the USA, 92.0\% [59], but lower than that reported for isolates in Nepal, 100\% [60], Mauritius, 100\% [61] and Trinidad, 100.0\% [41] and globally [34].

It is of public health significance that all (100.0\%) the 54 isolates of Salmonella from carcass swabs exhibited resistance to one or more antimicrobial agent, and more importantly that $72.2 \%$ of these were MDR isolates, thereby posing a potential for zoonotic spread of resistant Salmonella and a possible risk of therapeutic failure in workers at the informal market. There are reports of infections by Salmonella and other zoonoses associated with exposure of workers on farms and during processing of slaughtered livestock [36-38]. This is important considering that workers at the unregulated, illegal outlets of the informal market have been reported to practice poor hygiene in unsanitary environments [22,23], thus contributing to the cross-contamination of carcasses and exposure of the workers to the pathogen at these outlets. The possible exposure of consumers to improperly cooked chickens that are contaminated with resistant Salmonella is a food safety concern that can lead to salmonellosis with therapeutic implications, as documented by others [6-8].

The prevalence of resistance to six antimicrobial agents (tetracycline, doxycycline, streptomycin, spectinomycin, and sulfamethoxazole-trimethoprim) of Salmonella on chickens sampled and processed at the outlets in our study varied significantly across the townships as a result of the origin of live chickens. This may be due, in part, to the variable use or abuse of the antimicrobial agents on the farms from where the chickens are sourced. This aspect did not form part of our study. The lack of compliance with legislation governing the type and number of antimicrobial agents used in the livestock and human medicine in South African may be a causative factor in the development of antimicrobial resistance of Salmonella isolates studied [17,18,42], as similarly reported by others elsewhere [43,44].

It was of interest to have detected that the resistance pattern (E-OXT-S-SPE-DO) was predominant among isolates from the three types of samples and was detected at frequencies of $42.6 \%, 41.1 \%$ and $43.3 \%$ among carcass swabs, cloacal swabs and carcass drips, respectively. The differences were found not to be statistically significantly, which may be suggestive of cross-contamination of resistant Salmonella among the three types of samples. However, among the isolates which exhibited MDR, the frequency was statistically significantly ( $p=0.0308)$ lower for carcass swabs $(72.2 \%)$ compared with cloacal swabs $(92.8 \%)$ and carcass drip $(80.0 \%)$. These findings suggest that cross contamination may not be the only factor involved and therefore follow-up investigation may be required.

In our study the prevalence of antimicrobial resistant Salmonella in carcass drips was generally higher to antimicrobial agents compared to isolates from carcass swabs and 
cloacal swabs. It has also been reported that the prevalence of Salmonella was significantly higher than that found in either the carcass or cloacal swabs of the same chickens sampled from the informal market in Gauteng province [32].

A considerable variation of the prevalence of resistant Salmonella was detected within and between the nine serovars identified in the current study. Of relevance is that statistically significant differences were detected in the prevalence of resistance to tetracycline, doxycycline, streptomycin, and gentamycin among the serovars of Salmonella. This may reflect the differences in the antimicrobial resistance of Salmonella serotypes and the frequency of use or abuse of antimicrobial agents across the farms from where the chickens originated. Our findings agree with the reports of other studies conducted in Trinidad [41,46], Spain [62], Iran [63], USA [64], Korea [65], and Malaysia [66], where different prevalence of resistant Salmonella was detected among the serovars isolated.

\section{Conclusions}

Our findings of a high prevalence of resistance to antimicrobial agents and MDR isolates of Salmonella in chickens processed and retailed at outlets of the informal market in Gauteng province are likely to be indicative of potential zoonotic, food safety and therapeutic implications posed to workers at the outlets and consumers of improperly cooked Salmonella-contaminated chicken meat. The findings also indicate a high prevalence of resistant Salmonella on commercial poultry farms from where most of the slaughtered chicken originated in Gauteng province, South Africa. It is therefore imperative for workers at the informal market to practice good sanitation so as to prevent or reduce their exposure to resistant Salmonella. More importantly, it is prudent to enforce existing regulations on the use of antimicrobial agents on poultry farms in Gauteng province and in South Africa at large, in order to reduce the occurrence of antimicrobial resistant strains of Salmonella and other pathogens.

\section{Materials and Methods}

\subsection{Study Design}

The study was designed to determine the antimicrobial profiles of Salmonella strains isolated from chicken swabs, cloacal swabs and carcass drips collected from outlets of the informal market in Gauteng province, South Africa in an earlier study (32). The earlier study focused primarily on the prevalence, serovars and factors associated with Salmonella contamination of chicken carcasses at these outlets. The current study was designed to relate the prevalence of resistance to antimicrobial agents among Salmonella strains to the townships where the outlets sampled were located, the types of samples collected and processed and the serovars of the isolates. This study used a strategy to avoid duplication of isolates of Salmonella caused by the criteria employed to select and test isolates in the previous study [32].

\subsection{Selection of Informal Market Outlets for the Study}

To select outlets of the informal market for the study, different categories of outlets identified during the preliminary visits were used. The criteria used for the number of samples collected from each outlet and township, and from each selected outlet were described earlier [22,25]. The types of chickens sampled at the outlets included culled breeders, spent chickens, and broilers which originated from both large commercial and Developing Poultry Farmers Organization (DPFO), as well as from backyard farms in Gauteng province.

\subsection{Isolation, Identification and Confirmation of Salmonella}

The protocol used for the isolation and identification of Salmonella from chicken swabs, cloacal swabs and carcass drips was earlier described [14,25,32]. Briefly, each of the 151 chicken samples were inoculated into two enrichment broths, Rappaport Vassiliadis Soya (RVS) broth and Mueller-Kauffman tetrathionate (MKTT) broth and incubated for $24 \mathrm{~h}$ 
at 41.5 and $37^{\circ} \mathrm{C}$, respectively. Thereafter, the growths in the broths were inoculated and streaked for isolation on two selective media, xylose-lysine-desoxycholate (XLD) agar and Brilliance Salmonella agar (BSA) plates which were incubated aerobically at $37^{\circ} \mathrm{C}$ for $24 \mathrm{~h}$. Overall, each sample was therefore in effect plated on four agar media combinations of RVS/BSA, RVS/XLD, MKTT/BSA, and MKTT/XLD. Thereafter, isolates that exhibited phenotypic characteristic of Salmonella on BSA and XLD were subjected to biochemical tests to presumptively identify the organism [55]. Salmonella Typhimurium American Type Culture Collection (ATCC) 14028, was used as the positive control. The slide agglutination test, using Salmonella polyvalent $\mathrm{O}$ antisera (A-1 \& Vi) and a commercial test kit (Thermo Fisher, South Africa) was used to tentatively confirm the presumptive Salmonella isolates.

To confirm all tentatively identified Salmonella, DNA was extracted from each isolate by the boiling method $[16,67]$ followed by the use of conventional polymerase chain reaction (PCR) to detect the invA gene as described by Rodriguez-Lazaro et al. [67]. The following primer sequences were used to amplify a $284 \mathrm{bp}$ fragment of the invA gene, Forward: $5^{\prime}$ GTGAAATTATCGCCACGTTCGGGCAA $3^{\prime}$ and Reverse: $5^{\prime}$ TCATCGCACCGTCAAAGGAACC $3^{\prime}$ as described by Oliviera et al. [68].

\subsection{Determination of Serovars of Salmonella by PCR and Conventional Slide Agglutination Test}

The serovars of the isolates of Salmonella were determined using conventional PCR as described by Kim et al. [69]. The conventional PCR consisted of two five-plex and two monoplex reactions [69]. The monoplex was used to differentiate between serovars Dublin and Enteritidis with the PT4 primer, and serovars Anatum and Saintpaul were distinguished with the use of STM7 primer set. Table 5 shows the primer sets used in the study. For the study, Salmonella isolates that were typable by PCR were randomly selected from the nine serovars and subjected to the conventional agglutination test. The results were interpreted using the Kauffman-White scheme [70] at the Bacteriology Laboratory of the Onderstepoort Veterinary Research, South Africa.

Table 5. Primers used for molecular serotyping [70].

\begin{tabular}{|c|c|c|}
\hline \multicolumn{2}{|c|}{ Reaction 1 (STM) (Five-Plex) } & Product Size (bp) \\
\hline STM716F $5^{\prime}$ ACCGCTGCTTAATCCTGATGG $3^{\prime}$ & STM0716R 5' TGGCCCTGAGCCAGCTTTT $3^{\prime}$ & 187 \\
\hline STM1350R $5^{\prime}$ TCAAAATTACCGGGCGCA $3^{\prime}$ & STM1350R $5^{\prime}$ TTTTAAGACTACATACGCGCATGAA $3^{\prime}$ & 171 \\
\hline STM0839F $5^{\prime}$ TCCAGTATGAAACAGGCAACGTGT 3' & STM0839R 5' GCGACGCATTGTTCGATTGAT 3' & 137 \\
\hline STM4525F $5^{\prime}$ TGGCGGCAGAAGCGATG $3^{\prime}$ & STM4525R 5' CTTCATTCAGCAACTGACGCTGAG 3' & 114 \\
\hline STM4538F 5' TGGTCACCGCGCGTGAT 3' & $\begin{array}{l}\text { STM4538R 5' CGAACGCCAGGTTCATTTGT 3' } \\
\text { ction } 2 \text { (STY) (five-plex) }\end{array}$ & 93 \\
\hline STY0311F $5^{\prime}$ TGGTATGGTTAAGCGGAGAATGG $3^{\prime}$ & STY0312R 5' GAGAGTCATAGCCCACACCAAAG $3^{\prime}$ & 301 \\
\hline STY0346F 5' GGCTGGAGCAGCCTTACAAAA $3^{\prime}$ & STY0347R 5 $5^{\prime}$ AAGAGTTGCCTGGCTGGTAAAA $3^{\prime}$ & 262 \\
\hline STY2299F $5^{\prime}$ AАТCССССССССТСАAАAА $3^{\prime}$ & STY2300R 5' GGTACACCGTTTACTGTTTGCTGGA 3' & 220 \\
\hline STM3845F 5' ATATCTCATCGTCTCCTTTTCGTGT $3^{\prime}$ & STM3845R $5^{\prime}$ GAAGGTCCGGATAGGCATTCT $3^{\prime}$ & 181 \\
\hline STY2349F $5^{\prime}$ AATTACGGAGCAGCAGATCGAGG 3' & $\begin{array}{l}\text { STY2349R 5' TGCGGCCAGCTGTTCAAA 3' } \\
\text { ction } 3 \text { (PT4) (monoplex) }\end{array}$ & 124 \\
\hline PT4F 5' GGCGATATATAAGTACGACCATCATGG 3' & $\begin{array}{l}\text { PT4R 5' GCACGCGGCACAGTTAAAA 3' } \\
\text { ion } 4 \text { (STM7) (monoplex) }\end{array}$ & 225 \\
\hline STM2150F 5' CATAACCCGCCTCGACCTCAT $3^{\prime}$ & STM2150R $5^{\prime}$ AGATGTCGTGAGAAGCGGTGG $3^{\prime}$ & 101 \\
\hline
\end{tabular}

\subsection{Criteria for Selecting Isolates of Salmonella}

From all the 186 isolates of Salmonella recovered from the selective agar (RVS/BSA, RVS/XLD, MKTT/BSA, MKTT/XLD) and confirmed by PCR [32], to reduce the potential for duplicate isolates from each of the four types of samples, the following criteria were used for selection: (a) if a sample yielded several isolates that belonged to the same serovar, one isolate was randomly selected. (b) If a sample yielded isolates that belonged to more than one serovar, one isolate representing each serovar was selected. (c) If several isolates from the same sample were determined to be nontypable by PCR, one isolate was randomly selected.

Using the aforementioned criteria, a total of 170 isolates of Salmonella were selected for the study to determine their antimicrobial profiles. With the application of the criteria $(\mathrm{a}-\mathrm{c})$ 
and considering a bagged chicken as a unit from where three types of samples (carcass swabs, cloacal swabs and carcass drips) were collected, the frequency of resistance to antimicrobial agents in chicken-related Salmonella was determined (Table 1), i.e., chickenspecific frequency of resistance. The frequency of resistance to antimicrobial agents in 170 isolates of Salmonella according to the type of samples tested was also determined (Table 2), i.e., sample type specific frequency of resistance.

\subsection{Selection of Antimicrobial Agents Used in the Study}

Based on consultation with veterinarians in Gauteng province regarding the antimicrobial agents generally used in the livestock industry, including in poultry production, antimicrobial agents were selected for the study. Chloramphenicol was included for comparison and research purposes only since its use in food animals has been banned globally. A total of 16 antimicrobial agents belonging to eight classes of antimicrobial agents (Table 5) were selected for this study.

\subsection{Determination of Resistance of Salmonella Isolates to Antimicrobial Agents}

To determine the antimicrobial resistance profiles of Salmonella isolated from chickens sampled at the informal market outlets, the disc diffusion method was used according to the guidelines and interpretation of Clinical and Laboratory Standards Institute, CLSI [71]. The 16 antimicrobial agents (Thermo-Fisher Scientific, Hampshire, United Kingdom), the antimicrobial classes and their concentrations are shown in Table 6. Serotype Typhimurium ATCC 14028 was used as a reference strain.

Table 6. Classes and concentrations of antimicrobial agents used in the study.

\begin{tabular}{ccc}
\hline Class of Antimicrobial Agents & Type of Antimicrobial Agents Used & Concentration $(\mu \mathrm{g})$ \\
\hline Aminoglycosides & Spectinomycin (SPE) & 100 \\
& Streptomycin (S) & 10 \\
& Kanamycin (K) & 30 \\
Beta lactams & Gentamycin (CN) & 10 \\
& Ampicillin (AMP) & 30 \\
Cephalosporin & Amoxicillin-clavulanic acid (AMOX) & 30 \\
Fluoroquinolones & Ceftazidime (CAZ) & 30 \\
& Cefotaxime (CET) & 30 \\
& Nalidixic acid (NA) & 5 \\
Macrolides & Norfloxacin (NOR) & 15 \\
Phenicols & Ciprofloxacin (CIP) & 30 \\
Sulphonamides & Erythromycin (E) & $23.75 / 1.25$ \\
Tetracyclines & Chloramphenicol (C) & 30 \\
& Sulfamethoxazole-trimethoprim (SXT) & 30 \\
\hline
\end{tabular}

\subsection{Statistical Analysis}

The data were analyzed using Statistical Package for Social Science (version 25, IBM) to determine whether there were statistically significant differences in the frequency of isolation of antimicrobial resistant Salmonella (the independent variable), and dependent variables, specifically, the location of outlets in six townships, the types of samples processed (carcass swabs, cloacal swabs and carcass drips), and the serovars of the isolates. Data were presented as frequencies (percentages) and any association determined using chi square and Fisher's exact tests with the level of significance set at an alpha level of 0.05 .

Author Contributions: Conceptualization, A.A.A. and F.F.; methodology, T.M.M., A.A.A., N.G.; validation, N.G., T.M.M.; formal analysis, F.F., A.A.A., T.M.M.; investigation, T.M.M.; resources, N.G., A.A.A., F.F.; data curation, A.A.A., F.F. and T.M.M.; writing-original draft preparation, T.M.M.; writing-review and editing, A.A.A., N.G. and F.F.; supervision, N.G., F.F. and A.A.A.; project 
administration, F.F., N.G. and A.A.A.; funding acquisition, A.A.A.; All authors have read and agreed to the published version of the manuscript.

Funding: The project was funded by the Gauteng Department of Agriculture and Rural Development for funding this study (Research grant \# A02075). The APC was funded by the University of Pretoria.

Institutional Review Board Statement: The Ethics and Research committees of the Faculty of Veterinary Science, University of Pretoria, South Africa approved the protocol before the study commenced. The study was conducted according to the guidelines of the Declaration of Helsinki and approved by the Institutional Review Board (and Ethics Committee) of University of Pretoria (\#V053 by Ethics Committee on November 30, 2017; REC004-18 by Research Committee on February 08, 2018).

Informed Consent Statement: The consent of the owners of the outlets was obtained before they completed the questionnaires and prior to purchase of chickens by the research team.

Data Availability Statement: Data available in a publicly accessible repository. The data presented in this study are openly available in UPspace (https:/ / repository.up.ac.za/ (accessed on 27 February 2021) and in FigShare at https:/ / research.up.ac.za/ (accessed on 27 February 2021).

Acknowledgments: We are grateful to the laboratory staff at ARC-OVR Bacteriology section for their laboratory assistance. We also wish to thank the owners/vendors of the informal chicken outlets in Gauteng province for granting us permission to collect samples and to administer questionnaires on practices, throughput among others.

Conflicts of Interest: The authors declare no conflict of interest. The funders had no role in the design of the study; in the collection, analyses, or interpretation of data; in the writing of the manuscript, or in the decision to publish the results.

\section{References}

1. Barbour, E.K.; Ayyash, D.B.; Alturkistni, W.; Alyahiby, A.; Yaghmoor, S.; Iyer, A.; Yousef, J.; Kumosani, T.; Harakeh, S. Impact of sporadic reporting of poultry Salmonella serovars from selected developing countries. J. Infect. Dev. Ctries. 2015, 9, 1-7. [CrossRef]

2. Kumagai, Y.; Gilmour, S.; Ota, E.; Momose, Y.; Onishi, T.; Bilano, L.; Kasuga, F.; Sekizaki, T.; Shibuya, K. Estimating the burden of foodborne diseases in Japan. Bull. World Health Organ. 2015, 93, 540-549C. [CrossRef]

3. Oh, J.Y.; Kang, M.S.; An, B.K.; Song, E.A.; Kwon, J.H.; Kwon, Y.K. Occurrence of purulent arthritis broilers vertically infected with Salmonella enterica serovar Enteritidis in Korea. Poult. Sci. 2010, 89, 2116-2122. [CrossRef] [PubMed]

4. Rajagopal, R.; Mini, M. Outbreaks of salmonellosis in three different poultry farms of Kerala, India. Asian Pac. J. Trop. Biomed. 2013, 3, 496-500. [CrossRef]

5. EFSA: European Food Safety Authority. European Union summary report on antimicrobial resistance in zoonotic and indicator bacteria from humans, animals and food in 2014. EFSA J. 2016, 14, 4380. [CrossRef]

6. EFSA-ECDC: European Food Safety Authority and European Centre for Disease Prevention and Control. The European Union summary report on trends and sources of zoonoses, zoonotic agents and food-borne outbreaks in 2017. EFSA J. 2018, 16, 5500. [CrossRef]

7. Fonteneau, L.; Da Silva, N.J.; Fabre, L.; Ashton, P.; Torpdahl, M.; Muller, L.; Bouchrif, B.; El Boulani, A.; Valkanou, E.; Mattheus, W.; et al. Multinational outbreak of travel-related Salmonella Chester infections in Europe, summers 2014 and 2015. Eurosurveillance 2017, 22, 30463. [CrossRef]

8. ProMed Mail. Salmonellosis-Malaysia: (Kedah), Wedding Banquet, Fatal International Society for Infectious Diseases. 2013. Available online: http:/ / www.promedmail.org/direct.php?id=20131008.1989195 (accessed on 25 April 2015).

9. Durso, L.M.; Cook, K.L. Impacts of antibiotic. Use in agriculture: What are the benefits and risks? Curr. Opin. Microbiol. 2014, 19, 37-44. [CrossRef] [PubMed]

10. Lane, C.R.; LeBaigue, S.; Esanm, O.B.; Awofisyo, A.A.; Adams, N.L.; Fisher, I.S.; Grant, K.A.; Peters, T.M.; Larkin, L.; Davies, R.H.; et al. Salmonella serovar Enteritidis, England and Wales, 1945-2011. Emerg. Infect. Dis. 2014, 20, 1097-1104. [CrossRef]

11. Manishimwe, R.; Nishimwe, K.; Ojok, L. Assessment of antibiotic use in farm animals in Rwanda. Trop. Anim. Hlth. Prod. 2017, 49, 1101-1106. [CrossRef]

12. Sirdar, M.M.; Picard, J.; Bisschop, S.; Gummow, B. A questionnaire survey of poultry layer farmers in Khartoum state, Sudan, to study their antimicrobial awareness and usage patterns. Onderstepoort J. Vet. Res. 2012, 79, a361. [CrossRef]

13. Van, T.T.H.; Yidana, Z.; Smooker, P.M.; Coloe, P.J. Antibiotic use in food animals worldwide, with a focus on Africa: Pluses and minuses. J. Glob. Antimicrob. Resist. 2020, 20, 170-177. [CrossRef]

14. Roth, N.; Käsbohrer, A.; Mayrhofer, S.; Zitz, U.; Hofacre, C.; Domig, K.J. The application of antibiotics in broiler production and the resulting antibiotic resistance in Escherichia coli: A global overview. Poult. Sci. 2019, 98, 1791-1804. [CrossRef] [PubMed]

15. Njoga, E.O.; Onunkwo, J.I.; Okoli, C.E.; Ugwuoke, W.I.; Nwanta, J.A.; Chah, K.F. Assessment of antimicrobial drug administration and antimicrobial residues in food animals in Enugu state, Nigeria. Trop. Anim. Health Prod. 2018, 50, 897-902. [CrossRef] 
16. Nonga, H.E.; Simon, C.; Karimuribo, E.D.; Mdegela, R.H. Assessment of antimicrobial usage and residues in commercial chicken eggs from smallholder poultry keepers in Morogoro municipality, Tanzania. Zoonoses Publ. Health 2010, 57, 339-344. [CrossRef]

17. Mendelson, M.; Brink, A.; Gouws, J.; Mbelle, N.; Naidoo, V.; Pople, T.; Schellack, N.; van Vuuren, M.; Rees, H. South African One Health Stewardship Sub-Committee of the Ministerial Advisory Committee on Antimicrobial Resistance. The One Health stewardship of colistin as an antibiotic of last resort for human health in South Africa. Lancet Infect. Dis. 2018, 18, e288-e294. [CrossRef]

18. Theobald, S.; Etter, E.M.C.; Gerber, D.; Abolnik, C. Antimicrobial Resistance Trends in Escherichia coli in South African poultry: 2009-2015. Foodborne Pathog. Dis. 2019, 16, 652-660. [CrossRef] [PubMed]

19. Eagar, H.; Swan, G.; van Vuuren, M.A. A survey of antimicrobial usage in animals in South Africa with specific reference to food producing animals. J. S. Afr. Vet. Assoc. 2012, 83, 16. [CrossRef]

20. Darwish, W.S.; Eldaly, E.A.; El-Abbasy, M.T.; Ikenaka, Y.; Nakayama, S.; Ishizuka, M. Antibiotic residues in food: The African scenario. Jpn. J. Vet. Res. 2013, 61, S13-S22.

21. Rana, M.S.; Lee, S.Y.; Kang, H.J.; Hur, S.J. Reducing veterinary drug residues in animal products: A review. Food Sci. Anim. Resour. 2019, 39, 687-703. [CrossRef]

22. Adigun, F. Sanitary Practices and the Potential Staphylococcal and Coliform Health Risks Posed to Consumers of Dressed Chickens Sold in Informal Markets in Gauteng Province, South Africa. Master's Thesis, Veterinary Epidemiology, University of Pretoria, Onderstepoort, South Africa, 2017.

23. Oguttu, J.W. Participatory Risk Analysis of Street Vended Chicken Meat Sold in the Informal Market of PRETORIA, South Africa. Ph.D. Thesis, Department of Paraclinical Sciences, University of Pretoria, Onderstepoort, South Africa, 2015.

24. Oguttu, J.; Roesel, K.; McCrindle, C.; Hendrickx, S.; Makita, K.; Grace, D. Arrive alive in South Africa: Chicken meat the least to worry about. In Food Safety and Informal Markets: Animal Products in Sub-Saharan Africa; Routledge Publisher: Oxfordshire, UK, 2015; pp. 202-206.

25. Adigun, F.O.; Fasina, F.; Kidanemariam, A.; Gcebe, N.; Adesiyun, A.A. Prevalence and risk factors for staphylococcal and coliform carcass contamination of chicken slaughtered in the informal market in Gauteng Province, South Africa. Brit. Food J. 2020. [CrossRef]

26. Von Holy, A.; Makhoane, F.M. Improving street food vending in South Africa: Achievement and lessons learned. Int. J. Food Microbiol. 2006, 111, 89-92. [CrossRef]

27. Oguttu, J.W.; McCrindle, C.M.; Makita, K.; Grace, D. Investigation of the food value chain of ready-to-eat chicken and the associated risk for staphylococcal food poisoning in Tshwane Metropole, South Africa. Food Control 2014, 45, 87-94. [CrossRef]

28. South African Poultry Association (SAPA). Industry Profile. 2019. Available online: www.sapoultry.co.za/pdfdocs/sapa-broilerindustry-summary.pdf (accessed on 15 December 2020).

29. Department of Agriculture, Forestry and Fisheries for the Republic of South Africa (DAFF). Antimicrobial Resistance National Strategy Framework 2018-2024; Ministry of Health and DAFF: Johannesburg, South Africa, 2018; pp. 1-22.

30. Office International des Epizooties (OIE)_World Organisation of Animal Health. The OIE Strategy on Antimicrobial Resistance and the Prudent Use of Antimicrobials; WHO: Geneva, Switzerland, 2016.

31. Adigun, O.; Gcebe, N.; Jambwa, K.; Fasina, F.; Adesiyun, A.A. Molecular and phenotypic characterization of S. aureus strains isolated from carcass swabs and carcass drips of chickens slaughtered in the informal market in Gauteng Province, South Africa. J. Food Safety 2020, 40, e12806. [CrossRef]

32. Mokgophi, T.M.; Gcebe, N.; Fasina, F.; Jambwa, K.; Adesiyun, A.A. Prevalence, serotypes and risk factors for Salmonella spp. contamination of chicken carcasses sold in outlets of the informal market in Gauteng Province, South Africa. J. Food Prot. 2020. [CrossRef]

33. Gouws, P.A.; Brozel, V.S. Antimicrobial resistance of Salmonella isolates associated with retail chicken and a poultry abattoir. S. Afr. J. Sci. 2000, 96, 254-256.

34. Castro-Vargas, R.E.; Herrera-Sánchez, M.P.; Rodríguez-Hernández, R.; Rondón-Barragán, L.S. Antibiotic resistance in Salmonella isolated from poultry: A global overview. Vet. World 2020, 13, 2070-2084. [CrossRef]

35. Carnero, A.M.; Kitayama, K.; Diaz, D.A.; Garvich, M.; Angulo, N.; Cama, V.A.; Gilman, R.H.; Bayer, A.M. Risk for interspecies transmission of zoonotic pathogens during poultry processing and pork production in Peru: A qualitative study. Zoonoses Public Health 2018, 65, 528-539. [CrossRef]

36. Klous, G.; Huss, A.; Heederik, D.J.J.; Coutinho, R.A. Human-livestock contacts and their relationship to transmission of zoonotic pathogens, a systematic review of literature. One Health 2016, 2, 65-276. [CrossRef]

37. Nógrády, N.; Kardos, G.; Bistyák, A.; Turcsányi, I.; Mészáros, J.; Galántai, Z.; Juhász, A.; Samu, P.; Kaszanyitzky, J.E.; Pászti, J.; et al. Prevalence and characterization of Salmonella infantis isolates originating from different points of the broiler chicken-human food chain in Hungary. Int. J. Food Microbiol. 2008, 127, 162-167. [CrossRef] [PubMed]

38. Padungtod, P.; Kaneene, J.B. Salmonella in food animals and humans in northern Thailand. Int. J. Food Microbiol. 2006, 108, 346-354. [CrossRef] [PubMed]

39. Abatcha, M.G. Salmonella and Listeria monocytogenes: A review of prevalence and antimicrobial resistance in chickens and their processing environments. Adv. Anim. Vet. Sci. 2017, 5, 395-403. [CrossRef] 
40. Adesiyun, A.A.; Webb, L.; Musai, L.; Louison, B.; Joseph, G.; Stewart, A.; Samlal, S.; Rodrigo, S. Resistance to antimicrobial agents among Salmonella isolates recovered from layer farms and eggs in the Caribbean Region. J. Food Prot. 2014, 77, $2153-2160$. [CrossRef]

41. Khan, A.S.; Georges, K.; Rahaman, S.; Abdela, W.; Adesiyun, A.A. Antimicrobial resistance of Salmonella isolates recovered from chickens sold at retail outlets in Trinidad. J. Food Prot. 2018, 81, 1880-1889. [CrossRef] [PubMed]

42. Zishiri, O.T.; Mkhize, N.; Mukaratirwa, S. Prevalence of virulence and antimicrobial resistance genes in Salmonella spp. isolated from commercial chickens and human clinical isolates from South Africa and Brazil. Onderstepoort J. Vet. Res. 2016, 83, a1067. [CrossRef]

43. Ferri, M.; Ranucci, E.; Romagnoli, P.; Giaccone, V. Antimicrobial resistance: A global emerging threat to public health systems. Crit. Rev. Food Sci. Nutr. 2017, 57, 2857-2876. [CrossRef] [PubMed]

44. Mukerji, S.; O’Dea, M.; Barton, M.; Kirkwood, R.; Lee, T.; Abraham, S. Development and transmission of antimicrobial resistance among gram-negative bacteria in animals and their public health impact. Essays Biochem. 2017, 61, 23-35. [CrossRef] [PubMed]

45. Khan, A.S.; Georges, K.; Rahaman, S.; Abdela, W.; Adesiyun, A.A. Prevalence and serotypes of Salmonella spp. on chickens sold at retail outlets in Trinidad. PLoS ONE 2018, 13, e0202108. [CrossRef] [PubMed]

46. Kumar, N.; Krishna, M.; Georges, K.; Dziva, F.; Adesiyun, A.A. Prevalence, serovars and antimicrobial resistance of Salmonella spp. in cecal samples of chickens slaughtered in pluck shops in Trinidad. J. Food Prot. 2019, 82, 1560-1567. [CrossRef]

47. Rodrigo, S.; Adesiyun, A.; Asgarali, Z.; Swanston, W. Occurrence of selected foodborne pathogens on poultry and poultry giblets from small retail processing operations in Trinidad. J. Food Prot. 2006, 69, 1096-1105. [CrossRef] [PubMed]

48. Yang, B.; Cui, Y.; Shi, C.; Wang, J.; Xia, X.; Xi, M.; Wang, X.; Meng, J.; Alali, W.Q.; Walls, I.; et al. Counts, serotypes, and antimicrobial resistance of Salmonella isolates on retail raw poultry in the People's Republic of China. J. Food Prot. 2014, 77, 894-902. [CrossRef] [PubMed]

49. Bhuvaneswari, M.; Shanmughapriya, S.; Natarajaseenivasan, K. Prevalence of Multidrug-Resistant (MDR) Salmonella enteritidis in Poultry and Backyard Chicken from Tiruchirappalli, India. Microbiol. J. 2015, 5, 28-35. [CrossRef]

50. Akinola, S.A.; Mwanza, M.; Ateba, C.N. Occurrence, genetic diversities and antibiotic resistance profiles of Salmonella serovars isolated from chickens. Infect. Drug Resist. 2019, 12, 3327-3342. [CrossRef] [PubMed]

51. Ekwanzala, M.D.; Dewar, J.B.; Kamika, H.; Momba, M.N.B. Systematic review in South Africa reveals antibiotic resistance genes shared between clinical and environmental settings. Infect. Drug Resist. 2018, 11, 1907-1920. [CrossRef]

52. Igbinosa, I.H. Prevalence and detection of antibiotic-resistant determinant in Salmonella isolated from food-producing animals. Trop. Anim. Health Prod. 2015, 47, 37-43. [CrossRef] [PubMed]

53. Iwu, C.J.; Iweriebor, B.C.; Obi, L.C.; Basson, A.K.; Okoh, A.I. Multidrug-resistant Salmonella isolates from swine in the Eastern Cape province, South Africa. J. Food Prot. 2016, 79, 1234-1239. [CrossRef]

54. Madoroba, E.; Kapeta, D.; Gelaw, A.K. Salmonella contamination, serovars and antimicrobial resistance profiles of cattle slaughtered in South Africa. Onderstepoort Vet. Res. 2016, 83, 1-8. [CrossRef] [PubMed]

55. Mthembu, T.P.; Zishiri, O.T.; El Zowalaty, M.E. Molecular detection of multidrug resistant Salmonella isolated from livestock production systems in South Africa. Infect. Drug Resist. 2019, 12, 3537-3548. [CrossRef]

56. Ott, R. Antibiotic Resistance in Escherichia coli Causing Airsacculitis in Poultry in South Africa. Ph.D. Thesis, University of Bern, Bern, Switzerland, 2012.

57. Antunes, P.; Réu, C.; Sousa, J.C.; Peixe, L.; Pestana, N. Incidence of Salmonella from poultry products and their susceptibility to antimicrobial agents. Int. J. Food Microbiol. 2003, 82, 97-103. [CrossRef]

58. Yang, B.; Xi, M.; Wang, X.; Cui, S.; Yue, T.; Hao, H.; Wang, Y.; Cui, Y.; Alali, W.Q.; Meng, J.; et al. Prevalence of Salmonella on raw poultry at retail markets in China. J. Food Prot. 2011, 74, 1724-1728. [CrossRef] [PubMed]

59. Zhao, S.; Fedorka-Cray, P.J.; Freidman, S.; Mcdermott, P.F.; Walker, R.D.; Qaiyumi, S.; Foley, S.L.; Hubert, S.K.; Ayers, S.; English, L.; et al. Characterization of Salmonella Typhimurium of animal origin obtained from the national antimicrobial resistance monitoring system. Foodborne Pathog. Dis. 2005, 2, 168-181. [CrossRef] [PubMed]

60. Shrestha, A.; Regmi, P.; Dutta, R.K.; Khanal, D.R.; Aryal, S.R.; Thakur, R.P.; Karki, D.; Singh, U.M. First report on antimicrobial resistance of Salmonella isolated from poultry in Nepal. Vet. Microbiol. 2010, 144, 522-524. [CrossRef] [PubMed]

61. Phagoo, L.; Neetoo, H. Antibiotic resistance of Salmonella in poultry farms of Mauritius. J. World's Poult. Res. $2015,5,42-47$.

62. Álvarez-Fernández, E.; Alonso-Calleja, C.; García-Fernández, C.; Capita, R. Prevalence and antimicrobial resistance of Salmonella serotypes isolated from poultry in Spain: Comparison between 1993 and 2006. Int. J. Food Microbiol. 2012, 153, 281-287. [CrossRef] [PubMed]

63. Soltan Dallal, M.M.; Doyle, M.; Rezadehbashi, M.; Dabiri, H.; Sanaei, M.; Modarresi, S.; Bakhtiari, R.; Sharifiy, K.; Taremi, M.; Zali, M.R.; et al. Prevalence and antimicrobial resistance profiles of Salmonella serotypes, Campylobacter and Yersinia spp. isolated from retail chicken and beef, Tehran, Iran. Food Cont. 2010, 21, 388-392. [CrossRef]

64. Parveen, S.; Taabodi, M.; Schwarz, J.G.; Oscar, T.P.; Harter-Dennis, J.; White, D.G. Prevalence and antimicrobial resistance of Salmonella recovered from processed poultry. Food Prot. 2007, 70, 2466-2472. [CrossRef] [PubMed]

65. Kim, M.-S.; Lim, T.-H.; Jang, J.-H.; Lee, D.; Kim, B.-Y.; Kwon, J.-H.; Kwon, J.-H.; Choi, S.-W.; Noh, J.-Y.; Hong, Y.-H.; et al. Prevalence and antimicrobial resistance of Salmonella species isolated from chicken meats produced by different integrated broiler operations in Korea. Poult. Sci. 2012, 91, 2370-2375. [CrossRef] [PubMed] 
66. Thung, T.Y.; Mahydin, N.A.; Basrin, D.F.; Wan Mohamed Radzi, C.W.J.; Nakaguchi, Y.; Nishibuchi, M.; Radu, S. Prevalence and antibiotic resistance of Salmonella Enteritidis and Salmonella Typhimurium in raw chicken meat at retail markets in Malaysia. Poult. Sci. 2016, 95, 1888-1893. [CrossRef]

67. Rodriguez-Lazaro, D.; Gonzalez-García, P.; Delibato, E.; De Medici, D.; García-Gimeno, R.M.; Valero, A.; Hernandez, M. Next day Salmonella spp. detection method based on real-time PCR for meat, dairy and vegetable food products. Int. J. Food Microbiol. 2014, 184, 113-120. [CrossRef] [PubMed]

68. Oliveira, S.D.; Santos, L.R.D.; Schuch, M.T.; Silva, A.B.C.; Salle, T.P.; Canal, C.W. Detection and identification of Salmonellas from poultry-related samples by PCR. Vet. Microbiol. 2002, 87, 25-35. [CrossRef]

69. Kim, S.; Frye, J.G.; Hu, J.; Fedorka-Cray, P.J.; Gautom, R.; Boyle, D.S. Multiplex PCR-based method for identification of common clinical serotypes of Salmonella enterica subp. enterica. J. Clin. Microbiol. 2006, 44, 3608-3615. [CrossRef] [PubMed]

70. Grimont, P.A.; Weill, F. Antigenic Formulae of the Salmonella Serovars, 9th ed.; WHO Collaborating Centre for Reference and Research on Salmonella, Institut Pasteur: Paris, France, 2007.

71. Clinical and Laboratory Standards Institute. Performance Standards for Antimicrobial Susceptibility Testing; CLSI: Wayne, PA, USA, 2017. 